\title{
ALGUMAS CONSIDERAÇÕES SOBRE A PRESENÇA CHINESA NA BOLÍVIA
}

\author{
Diego Pereira Siqueira $^{1}$
}

\begin{abstract}
RESUMO
Este artigo tem por objetivo entender o contexto sócio-econômico em que ocorre a penetração das empresas chinesas na Amazônia boliviana. Para isso, analisa tanto as estratégias do Estado chinês para a projeção de sua influência quanto o contexto interno boliviano, marcado pela ascensão ao comando do Estado de um partido de origem camponesa que promove um processo de acumulação capitalista de camadas populares (o capitalismo andino-amazônico, nas palavras do ex-vice presidente Garcia Linera) e cujo horizonte desenvolvimentista viu no capital chinês uma grande oportunidade para a entrada rápida de ingressos. No entanto, os custos ambientais e sociais da atuação das empresas chinesas têm sido elevados.
\end{abstract}

Palavras-chave: Empresas chinesas. MAS. Capitalismo andino-amazônico.

\begin{abstract}
This article aims to understand the socio-economic context in which the penetration of Chinese companies in the Bolivian Amazon occurs. For that, it analyses both the strategies of the Chinese state for the projection of its influence and the internal Bolivian context, marked by the rise to state command of a party of peasant origin that promotes a process of capitalist accumulation of popular layers (the Andean-Amazonian capitalism, in the words of former vice-president Garcia Linera) and whose developmentalist horizon saw in the Chinese capital a great opportunity for the rapid entry of tickets. However, the environmental and social costs of Chinese companies' actions have been high.
\end{abstract}

Keywords: Chinese companies; MAS; Andean-Amazonian capitalism

Submetido em: 02.01.2020 Aprovado em: 27.02.2020

\section{INTRODUÇÃO}

A China hoje é, indiscutivelmente, a maior economia mundial e seu dinamismo guia o crescimento dos países de todos os continentes ${ }^{2}$. Sua ascensão, o relativo declínio dos Estados

\footnotetext{
1 Bacharel em Letras Português pela USP, Mestre e Doutor em Ciências pelo Programa Interdisciplinar em Integração da América Latina (Prolam-USP), especializado em tradução dos idiomas inglês e espanhol. Possui experiência como professor universitário no curso de Serviço Social e arte-educador em projetos de fotografia. E-mail: diegofolkmetal@gmail.com

${ }^{2}$ O FMI calcula que o PIB chinês em 2018 foi de US\$14,941.148 (o dobro de 2011). Sua média de crescimento tem sido de $10 \%$ ao $\quad$ ano. https://www.imf.org/external/pubs/ft/weo/2013/01/weodata/weorept.aspx?pr.x=66\&pr.y=13\&sy=2011\&ey=201 $8 \& \mathrm{scsm}=1 \& \mathrm{ssd}=1 \&$ sort $=$ country $\& \mathrm{ds}=. \& \mathrm{br}=1 \& \mathrm{c}=924 \& \mathrm{~s}=\mathrm{NGDPD} \% 2 \mathrm{CNGDPDPC} \% 2 \mathrm{CPPPGDP} \% 2 \mathrm{CPPPPC} \%$ 2CLUR\&grp=0\&a $=$. Consultado em: 13/12/2019. Segundo relatório do Banco Mundial, as importações chinesas cresceram até alcançarem 18,8\% do PIB nos primeiros nove meses de 2018, comparadas com 15,3\% no mesmo período em 2017. Apesar da tensão comercial com os EUA, o excedente comercial da China com esse país aumentou para US\$ 295 bilhões nos primeiros 11 meses de 2018, contra US\$ 252 bilhões no mesmo período de 2017. http://pubdocs.worldbank.org/en/917591545202039807/CEU-Dec-2018-EN.pdf.
} 
Unidos e a reorganização que esses fatos imprimem às Relações Internacionais trazem ao estudioso desse campo o desafio de tentar apreender e interpretar as múltiplas dimensões desse processo.

Analistas já falam no fim do Século Americano e o início do Século do Pacífico, com essa grande área geográfica que abarca a China e países como Japão, Coreia do Sul e Vietnã se configurando como o novo centro de gravidade do capitalismo internacional ${ }^{3}$. Mais recentemente, o programa de investimentos em infraestrutura, conhecido como o projeto One Belt One Road (OBOR), lançado oficialmente pelo presidente Xi Jinping em 2015 e que envolve de forma direta ou indireta 68 países (inclusive a América Latina), é o exemplo mais claro das ambiciosas projeções econômicas e geopolíticas chinesas. A iniciativa visa múltiplos objetivos, como o fortalecimento da diplomacia econômica, a abertura e promoção do comércio internacional e a garantia do fornecimento seguro de matérias-primas, além de buscar dar vazão ao excesso de capacidade instalada ociosa das empresas chinesas.

Complementando esses planos de integração física, a China também tem promovido uma nova estrutura de financiamentos, que pode constituir no futuro próximo uma rede alternativa aos organismos financeiros tradicionais controlados pelos EUA, como o FMI e o Banco Mundial: o Silk Road Fund, o Novo Banco de Desenvolvimento e o Banco Asiático de Investimento em Infraestrutura, com um capital disponível conjunto que supera os US\$250 bilhões ${ }^{4}$.

Segundo o Ministério de Comércio Exterior da China, desde 2015 já foram assinados mais de 13 mil contratos de investimentos ligados ao OBOR, totalizando US\$ 241 bilhões. O tamanho e o escopo dessa alternativa indicam, se a maioria de seus projetos se concretizar, que o poder econômico e político da China aumentará de forma acentuada nessa grande porção do globo, fato intensificado pelo recente abandono, dos Estados Unidos, do Tratado de Associação Transpacífico (TPP) ${ }^{5}$.

Essa projeção da influência econômica e política chinesa tem como característica específica o papel protagonista que o Estado tem desempenhado, seja na orientação dos investimentos produtivos (através de seus planos quinquenais e no uso de grandes empresas estatais) quanto na atuação de uma diplomacia que tem tido uma orientação sistemática,

\footnotetext{
${ }^{3}$ Ver, a esse propósito, a excelente obra de Giovani Arrighi, Adam Smith em Pequim (São Paulo: Boitempo, 2017).

${ }^{4}$ Dados retirados do Informativo do Conselho Empresarial Brasil-China no 78 , julho de 2017. Disponível em: http://cebc.org.br/sites/default/files/cebc_alerta_ed_78_obor_final.pdf.

${ }^{5}$ https://www.google.com.br/search?client=opera\&q=EUA+abandonam+parceria+trans-

pacífica\&sourceid=opera\&ie=UTF-8\&oe=UTF-8. Consultado em: 13/12/2019.
} 
pouco mudando ao longo dos últimos quarenta $\operatorname{anos}^{6}$, centrada na caracterização da China como um país em desenvolvimento, não-intervencionista, favorável ao multilateralismo e à cooperação.

Na América Latina, o aumento da presença econômica da China tem sido rápido e avassalador. De acordo com a Cepal (2015), o comércio da região, com o gigante asiático, aumentou 22 vezes desde o ano 2000. Não obstante, a composição desses intercâmbios revela uma enorme assimetria: as exportações latino-americanas concentram-se quase que totalmente em recursos naturais como minerais, hidrocarbonetos e produtos agrícolas como a soja, enquanto que a China vem exportando para a região produtos industrializados de alta densidade tecnológica, como máquinas e equipamento de transporte, manufaturas médias e leves, e produtos relacionados às telecomunicações.

Isso levanta o espectro de uma reprodução das antigas relações de dependência que reservavam aos países latino-americanos o papel de fornecedores de matérias-primas e consumidores de produtos industrializados de alto valor agregado, argumento que ganha força à medida que aumenta o déficit comercial da região em seus intercâmbios com a China. Autores como Osório (2012), aliás, apontam para o desenvolvimento de um novo padrão exportador de especialização produtiva, concentrado em poucos produtos ligados a cadeias globais de valor e indissociável da demanda chinesa de matérias-primas.

Da parte do governo chinês, sua principal preocupação na região é assegurar um fornecimento estável de produtos primários para seu mercado doméstico, e tem se materializado nos significativos empréstimos que oferece para projetos de infraestrutura e integração física das economias regionais, pensados em função de redução dos custos e maior facilidade e rapidez no acesso aos mercados do Pacífico.

Em 2010, os chineses concederam créditos de US\$ 37 bilhões na região, soma que excedeu o total do BID e do Banco Mundial (BM) para o mesmo período. Estima-se que a China tenha concedido empréstimos no valor aproximado de US\$ 86 bilhões a países da América Latina desde 2005 até 2013. Esse montante é mais alto que o conjunto de empréstimos concedidos pelo BM, o BID e o Banco de ExportaçãoImportação dos Estados Unidos (US Ex-Im Bank) nesse mesmo período; contudo, esse valor ainda é menor que o emprestado pelo Banco Nacional de Desenvolvimento Econômico e Social (BNDES) dentro do Brasil no mesmo

\footnotetext{
${ }^{6}$ De fato, a caracterização da China como um país do "Terceiro Mundo", em oposição às grandes potências mundiais da época (Estados Unidos e União Soviética) e, portanto, sua unidade de interesses com outros países da Ásia, África e América Latina, foi um importante componente da política externa chinesa ainda sob o governo de Mao Zedong. Após a morte do líder revolucionário, seus sucessores mantiveram essa caracterização, alterando algumas nuances e adequando-a à nova terminologia adotada após a queda do muro de Berlim, de país "em desenvolvimento", mais uma vez enfatizando a unidade de interesses com outros países da mesma situação, como fica claro, por exemplo, nos dois policy papers sobre América Latina emitidos pelo governo chinês. Para mais detalhes, ver KISSINGER, Henry: Sobre a China (Objetiva: 2011).
} 
intervalo. Em 2012, o China Ex-Im Bank e o BID anunciaram um fundo conjunto de U\$ 1 bilhão para investimentos do setor privado e público na América Latina. Em 2013 o Banco Popular da China anunciou o investimento de US\$ 2 bilhões em projetos do BID (...). (MORENO, 2015, p. 28).

A importância estratégica que a América Latina está assumindo como fornecedora de matérias-primas é indicada pelo documento oficial emitido pelo governo chinês em abril de 2009, China's policy paper on Latin America and the Caribbean, uma iniciativa inédita que delineia os princípios e diretrizes de um relacionamento estratégico com a região, centrados no aprofundamento da cooperação e no benefício mútuo para ambos os lados (a política "winwin”), princípios que foram reafirmados em 2016 com um segundo policy paper. Nos dois documentos, a China se compromete a fornecer ajuda técnica e econômica aos países da região sem atá-las a qualquer condicionamento de ordem política. Os investimentos chineses têm sido fundamentais, por exemplo, para o governo de Nicolás Maduro na Venezuela, que graças a eles logrou contornar a grave crise econômica e institucional que o país vem atravessando e suportar o crescente isolamento internacional ${ }^{7}$.

Essa nova realidade econômica possui importantes implicações geopolíticas, ainda não totalmente claras, já que a China vai deslocando os Estados Unidos como o principal parceiro comercial da América Latina, e essa nova posição acompanha uma profunda reorganização do espaço econômico desses países, alterando de forma decisiva a geoeconomia sul-americana e reforçando as tendências estruturais rumo a uma reprimarização econômica ${ }^{8}$.

A forma como a presença chinesa assume na América Latina também apresenta mudanças ao longo do tempo. Se na primeira década desse século as exportações da China para a região eram compostas principalmente de máquinas leves, a partir de 2010 passam a ganhar destaque máquinas e equipamentos de transporte, chegando ao fim dessa década com

\footnotetext{
${ }^{7}$ A Venezuela, entre 2005-2015, recebeu um total de 56 bilhões de dólares em empréstimos chineses, 47,44\% do total para toda a região (AGRAMONT \& BONIFAZ, 2018, p. 69). Para mais informações, ver: https://www.efe.com/efe/brasil/portada/china-e-venezuela-assinam-28-acordos-de-coopera-oestrategica/50000237-3749732. Consultado em: 15/12/2019.

${ }^{8}$ Para ficar apenas em um caso, entre 2004 e 2014 a China assumiu a posição de principal fornecedor de bens industriais para o Brasil, tendo as exportações decuplicado, expandindo-se de $6 \%$ (US\$ 3,6 bilhões) para 16\% (US\$ 37 bilhões) do total importado pelo Brasil. Os cinco produtos mais importantes nas compras da China são equipamentos de comunicação, informática, aparelhos de áudio e vídeo, equipamentos eletrônicos e produtos químicos orgânicos, todos eles bens de mais alto conteúdo tecnológico. O fluxo de bens intensivos em tecnologia cresceu nesses dez anos de US\$ 2,1 bilhões para US\$ 20,8 bilhões, atingindo quase $60 \%$ das importações totais de mercadorias chinesas realizadas pelo Brasil. No sentido das exportações do Brasil para a China, o crescimento no mesmo período foi de cerca de seis vezes, saindo de US\$3,8 bilhões para US\$23,8 bilhões, dos quais $92,8 \%$ foram de commodities (agroindústrias de primeiro processamento, insumos básicos industriais e petróleo). As exportações de bens de mais alto conteúdo tecnológico, que eram de 11,2\% do total em 2004, reduziram-se para 2,6\% em 2014 (MORENO, 2015).
} 
$100 \%$ das importações da China constituídas por manufaturados, e destes, $60 \%$ são bens de alta tecnologia (AGRAMONT \& BONIFAZ, 2018, p. 35).

Outro aspecto significativo são os Investimentos Estrangeiros Diretos (IED) provenientes do gigante asiático, que do mesmo modo sofreram mudanças significativas ao longo desse período.

Desde o ano 2010, o investimento estrangeiro direto da China na América Latina e Caribe teve um crescimento significativo, transformando de maneira gradual a relação com as economias regionais, de uma dominada principalmente por transações comerciais (a compra, por parte da China, de produtos primários da região e a venda de manufaturas industriais) para uma onde as empresas chinesas têm uma presença física importante na América Latina, contribuindo não apenas para a geração de emprego, mas também como fonte de ingressos para os governos locais e como protagonistas na construção de uma infraestrutura de transporte, telecomunicações e turismo. Como consequência desta mudança de enfoque, a China hoje possui maior impacto nas dinâmicas sociopolíticas da América Latina e tem expandido seu soft power na região... Neste processo, as empresas chinesas começaram a consolidar-se como atores locais e estão começando a entender como utilizar esta influência para administrar os riscos e buscar oportunidades de negócios na região latino-americana. (RÓLDAN et al., 2016, p. 73, tradução nossa, grifos dos autores).

Os setores em que as empresas chinesas vêm ganhando espaço são o de serviços, transportes e energia. Além de IEDs, outro mecanismo que garante sua presença são os empréstimos diretos do governo chinês ou de suas instituições financeiras (como o Exmbank), que, se não há exigências políticas, não obstante, possuem como cláusula de condicionalidade a obrigação de contratar empresas chinesas para a execução das obras.

\section{AMÉRICA LATINA: O CICLO PÓS-LIBERAL}

O período histórico que testemunhou o aumento da presença chinesa na região coincidiu com o ciclo político dos chamados governos progressistas, liderados por forças de esquerda ou centro-esquerda, que em seu conjunto tinha por denominador comum o rechaço ao modelo neoliberal que predominou na década de 1990 e a implementação de uma nova estratégia econômica que certos autores denominam como neodesenvolvimentismo? .

Todavia, todos esses governos, apesar de apresentarem diferenças importantes com a política econômica neoliberal anterior, optaram pelo aprofundamento do modelo econômico

\footnotetext{
9 Katz (2016, p. 160-161) resume o conjunto de propostas neodesenvolvimentistas a cinco pontos: 1) intensificação da intervenção estatal, mas sem voltar às antigas práticas keynesianas; 2) uso da política econômica não apenas para atuações na conjuntura, mas como um instrumento central para o crescimento, cuja prioridade é manter o déficit fiscal reduzido; 3) retomada da industrialização para multiplicar o crescimento urbano; 4) redução da defasagem tecnológica, mediante acordos com empresas transnacionais para conseguir transferência de conhecimentos; 5) imitar o avanço exportador do Sudeste Asiático, visto como modelo de sucesso de industrialização recente.
} 
exportador de especialização produtiva, relegando a indústria a um papel secundário. A necessidade de dar uma rápida resposta aos anseios de melhoria nos padrões de vida de seus eleitores, aliada à expectativa de grandes ingressos, induziu esses governos a aderirem ao que Maristella Svampa (2017) chama de "Consenso das Commodities": a aceitação da divisão internacional do trabalho que reservava à América do Sul o papel de fornecedora de matériasprimas, e a aposta que a alta do preço desses elementos, puxada pelo extraordinário crescimento da economia chinesa, significaria a chave para um período prolongado de crescimento e aumento do bem-estar geral ${ }^{10}$.

Um componente essencial do Consenso das Commodities é o fortalecimento do Estado como agente produtor e/ou regulador, que também oferece um conjunto de políticas sociais dirigidas aos setores mais vulneráveis e empobrecidos, "cuja base mesma é a renda extraordinária associada ao modelo extrativo-exportador" (SVAMPA, 2017, p. 56). Ao lado disso, há o fortalecimento das frações das burguesias locais que controlam as atividades ligadas a esse boom, como o agronegócio e as grandes empresas de construção civil, em associação com esse mesmo Estado.

O fortalecimento econômico dessas camadas projeta ainda o aumento de sua influência política, e através dela buscam expandir as condições para seu processo de acumulação, por meio da ampliação das fronteiras agrícolas, flexibilização das leis ambientais, superexploração do trabalho e abertura econômica. A necessidade dos ingressos provenientes do setor exportador levou os governos progressistas a serem seus aliados objetivos, entrando em conflito até mesmo com sua base social originária, como fica evidente no balanço do governo evista na Bolívia.

\section{BOLÍVIA: DA REBELIÃO ANTI-NEOLIBERAL AO CAPITALISMO ANDINO- AMAZÔNICO}

A vitória do partido MAS de Evo Morales em 2006 foi resultado da onda de rebeliões iniciada na Bolívia em 2000 com a chamada Guerra da Água e que colocou em questão não apenas um governo ou um partido, mas toda a institucionalidade neoliberal criada com as reformas dos anos 1980. A postura anticapitalista, antiestatal e de rejeição à mercantilização dos recursos naturais dos diversos movimentos participantes dessa mobilização foi sintetizada no discurso do Bem Viver, ou seja, a construção de um meio de vida pautado por outras

\footnotetext{
${ }^{10}$ Como resultado disso, a América Latina tem testemunhado na última década um aumento exponencial da superexploração de bens naturais, construção de grandes projetos de represas e vias de comunicação e ampliação das fronteiras agrícolas, que invadem territórios antes reservados para a preservação ambiental ou ocupados por povos originários, quilombolas e comunidades.
} 
lógicas que não a instrumental-racionalista, que colocava a descolonização cultural e a harmonia com o meio ambiente como seus principais eixos ${ }^{11}$.

Contudo, o ator social que logrou conquistar a hegemonia dentro deste processo de mudanças e conduzi-lo rumo a uma nova institucionalidade, o partido camponês MAS-IPSP (Movimiento al Socialismo - Instrumento Político por la soberania de los pueblos), optou pelo aprofundamento do modelo econômico primário-exportador.

É precisamente na Bolívia que testemunhamos o fortalecimento do poder estatal, mencionado anteriormente, em um momento em que suas bases de legitimidade estavam totalmente solapadas pelo assédio dos movimentos sociais. Essa tarefa coube ao partido de camponeses cocaleiros MAS, herdeiro de uma longa tradição de ambiguidade do movimento camponês que, historicamente, associou-se ao Estado mesmo quando se enfrentava contra suas políticas. Em sua trajetória, o movimento cocaleiro mostrou uma inegável capacidade de articulação com outros setores das classes populares bolivianas, construindo-se assim como uma alternativa de poder aos desgastados partidos da era neoliberal (URQUIDI, 2006).

No entanto, sua perspectiva política, evidenciada já na época da Assembleia Constituinte, convocada em 2006 para a "refundação" da Bolívia, apontava não para a superação radical do capitalismo dependente boliviano, mas para uma pactuação com a antiga elite econômica que tinha por finalidade a construção de uma nova correlação de forças entre as classes sociais, onde essa reconhecesse a emergência de uma nova camada que tinha interesse no compartilhamento do poder.

Vencida a etapa constituinte, assegurado pelo Estado o controle da renda do setor de hidrocarbonetos e derrotada politicamente a oposição das oligarquias agroempresariais (centradas nos departamentos [estados] da chamada região da Meia Lua), o MAS passa a ter absoluta hegemonia para colocar em prática sua visão estratégica: a construção do que chamava de capitalismo andino-amazônico, tal como teorizado e defendido pelo vicepresidente Garcia Linera em diversos escritos ${ }^{12}$. Seu programa econômico mantém e aprofunda os marcos da dependência ao configurar a existência de um Estado do tipo rentista, apoiado nas atividades extrativas de recursos naturais. Ao lado disso, aproxima-se da antiga elite agroexportadora, que obteve diversas garantias para expandir a fronteira agrícola.

Para assegurar sua hegemonia, o MAS precisou pôr em prática diversos esquemas de cooptação dos movimentos sociais, entre eles a estatalização (incorporação desses

\footnotetext{
${ }^{11}$ Para mais informações, ver o livro de ACOSTA, O bem viver (Elefante: 2016).

${ }^{12}$ Para mas informações, conferir a entrevista de Linera a Svampa e Stefanoni: http://bibliotecavirtual.clacso.org.ar/ar/libros/osal/osal22/AC22SvampaStefanoni.pdf. Consultado em: $18 / 12 / 2019$.
} 
movimentos ou de seus dirigentes a órgãos do governo, para assim diluir sua capacidade mobilizatória e envolvê-los na lógica burocrática) ou a perseguição pura e simples aos que resistiam ao avanço das atividades extrativistas. A controvérsia em torno da construção da estrada do TIPNIS é emblemática dessa relação que o MAS estabeleceu com os movimentos sociais que entram em choque com seus objetivos políticos e econômicos ${ }^{13}$. Outro ponto que evidencia o caráter de classe do governo evista é a questão agrária.

A reforma agrária foi um dos pontos de atrito entre a oposição autonomista e o MAS durante a Assembleia Constituinte. Aqui, a fisionomia pequeno-burguesa do núcleo duro do partido governante determinou que a resolução da questão seguisse a lógica de "pacto democrático" entre as principais forças:

\begin{abstract}
O que configura uma reforma agrária do tipo branda e reformista: a distribuição quantitativa de pequenas parcelas na periferia da fronteira agrícola (terras improdutivas e de difícil acesso aos mercados agrícolas) com outorga de empréstimos governamentais de cunho leve aos pequenos produtores. Trata-se de uma nova modalidade de reforma agrária com expansão de minifúndios e proteção velada do grande latifúndio no leste do país, e que serve como instrumento de concessão econômico-social para o camponês e indígena com o fim de obter lealdade política ao regime vigente e ampliar sua base social de apoio, como se dera na primeira reforma agrária de 1953, consolidando-se tal prática ao longo dos anos 1950, 1960 e 1970 durante os governos do MNR e os governos militares. O que, a nosso ver, reforçaria a outra face do padrão econômico boliviano, predominante ao longo do século XX: o agrário-camponês. A outra face desse padrão é o mineiroextrativo. (GIL, 2008, p. 183).
\end{abstract}

Concluído o processo constituinte, observa-se uma lenta reaproximação entre o partido dirigente e representantes da burguesia agroindustrial, visando a conclusão do "pacto democrático" propugnado pelo MAS. Após a eleição do segundo mandato de Evo Morales, a política econômica posta em marcha pelo Estado colocará em primeiro plano a necessidade de um incremento das exportações agrícolas e minerais, coincidindo com o boom por produtos primários (em especial cana de açúcar, soja, milho e sorgo). Isso criará o terreno para a reconciliação entre o partido indígena e burguesia agroindustrial. Um marco dessa aproximação será a Lei № 337 de janeiro de 2013: seus críticos a acusam de legitimar os desmatamentos ilegais de terras florestais para fins agropecuários realizados entre 1996 e 2011, em contradição com os dispositivos da própria Constituição e da Lei de Recondução Comunitária da Reforma Agrária, aprovada pouco antes. Com ela, donos de terrenos onde houve desmatamento podem regularizar a propriedade destes, sem temer uma possível desapropriação.

\footnotetext{
${ }^{13}$ Para mais informações sobre os conflitos dos movimentos sociais bolivianos com o governo evista, ver o livro de Machado \& Zibechi (2016).
} 
Segundo dados da ANAPO (Associação Nacional de Produtores de Oleaginosas), a superfície desmatada sem autorização chega a 4,3 milhões de hectares. Porém, outros dados recolhidos pelo Ministério de Desarrollo Rural y Tierras indicam que existem 5,5 milhões de hectares de desmates ilegais, dos quais 38\% respondem a criadores de gado, $28 \%$ a agroindustriais, $17 \%$ a colonizadores estrangeiros, $12 \%$ a camponeses e $5 \%$ a povos indígenas (ORMACHEA \& RAMIREZ, 2013, p. 21-22). A intenção de incrementar a exportação agrícola por parte dessa lei também fica clara com a seguinte declaração de Garcia Linera na época, de que sua aprovação ocorre em:

\begin{abstract}
Um bom momento para relançar a produção agropecuária na Bolívia, há estabilidade econômica e política, há dinheiro nos bancos, há mercado, se está melhorando as vias de transporte, há regras claras, não há insegurança jurídica a respeito da propriedade, não há risco de sanções ou desapropriações, com o que, se agora há 3,5 milhões de hectares cultivados, (...) o que se pode habilitar agora com esta Lei e este decreto são outros 4 milhões de hectares. (In: ORMACHEA \& RAMIREZ, 2013, p. 23, tradução nossa).
\end{abstract}

A principal intenção do governo com essa lei era de criar um ambiente jurídico e político estável que propiciasse o crescimento do setor exportador capitalista. Após 12 anos de governo evista, a estrutura real do setor agrário aponta para uma continuidade da grande propriedade que historicamente tem sido um dos pilares do capitalismo boliviano. Segundo dados do CEDLA, as médias e grandes empresas agrícolas possuem 38 milhões de hectares, os camponeses 17 milhões, e as TCO (Terras Comunitárias de Origem) ao redor de 22 milhões de hectares (ORMACHEA \& RAMIREZ, 2013, p. 85).

Para garantir a manutenção desse projeto e sua supremacia política, o governo do MAS, ao lado do fortalecimento da repressão estatal aos movimentos sociais que não se coadunam com o avanço do extrativismo, buscou desqualificar os críticos mediante a construção de um discurso nacionalista modernizante que criminaliza as mobilizações ambientais e comunitárias como expressões de um "ambientalismo colonial", impulsionado por "ONGs" estrangeiras aliadas ao velho poder "patrimonial-latifundiário", interessadas em manter o povo boliviano mergulhado na pobreza e na submissão pré-capitalista ${ }^{14}$. Quando confrontado por mobilizações de povos originários, como no TIPNIS, ou para mostrar que conta com apoio popular, o evismo mobilizava suas bases sociais encontradas entre cocaleiros, mineiros cooperativistas ou pequenos comerciantes urbanos, que constituem camadas médias em processo de acumulação.

\footnotetext{
${ }^{14}$ Mais uma vez, é Garcia Linera que estabelece os marcos ideológicos desse discurso em sua obra "Geopolítica de la Amazonía" (2013).
} 


\section{PEQUENA BURGUESIA COMERCIAL INDÍGENA}

O modelo econômico primário-exportador, junto com as benesses distribuídas pelo Estado rentista, originou um período de prosperidade que se refletiu na enorme liquidez bancária e no fortalecimento de setores como o de construção e de importação de bens de consumo populares, e visibilizou a ascensão de novas elites econômicas comerciais de origem popular e indígena, que se aproveitam dos interstícios da institucionalidade para promover seus negócios.

No livro Hacer plata sin plata (PIEB: 2013, coordenado pelo pesquisador Nico Tassi) há uma análise desse setor das novas camadas médias emergentes. Em sua grande maioria de origem aimará, dominam o comércio de bens importados em cidades como El Alto e La Paz. Operando no território ambíguo entre a informalidade e o reconhecimento legal, com amplos conhecimentos sobre suas áreas de atuação, possuindo uma profusa rede de contatos, dotados de grande flexibilidade para satisfazer as exigências de seus clientes, tais comerciantes têm sabido se beneficiar da prosperidade econômica dos anos recentes para, inclusive, internacionalizar seus negócios. É cada vez mais comum que muitos deles estabeleçam contato direto com fabricantes na China, viajem regularmente para aquele país e voltem carregados de grandes quantidades de produtos, que são distribuídos por uma ampla rede por todo o território nacional. Segundo Rea Campos, a emergência desses novos agentes econômicos é resultado:

(...) de uma afinidade eletiva entre certos condicionantes externos, como os efeitos do nacionalismo revolucionário que a população indígena começou a experimentar ao final da década dos anos 1960 (a expulsão da população indígena para os centros urbanos e a massificação educativa) e das mudanças estruturais de corte neoliberal desde os anos oitenta (a flexibilização do mercado de trabalho que os excluiu para as margens informais) e a capacidade - criatividade cultural - que estes sujeitos indígenas desenvolveram para enfrentar situações adversas em um cenário de contração da economia nacional e de expansão e influxo da economia comercial asiática no mercado nacional. (REA CAMPOS, 2016, p. 376, tradução nossa).

A prosperidade desse setor reflete-se, por exemplo, no fenômeno da construção de grandes mansões nos bairros populares de El Alto (os chamados “cholets”), que servem tanto como residência como sede de seus negócios ${ }^{15}$. Sua influência, tanto econômica quanto

\footnotetext{
${ }^{15}$ Entretanto, há uma grande diversidade dentro dessa categoria de comerciantes informais. A maioria delas, estatisticamente, entra na categoria ocupacional de "trabalhadores por conta própria", cuja proporção em cidades como Oruro chega a mais de $60 \%$ da população ocupada, e cuja diferenciação de capital pode ser significativa. Enquanto os pequenos comerciantes podem contar com um volume de capital de menos de mil dólares a um máximo de US\$ 15 mil, o estoque de capital manejado pelos grandes comerciantes pode flutuar de US\$100 mil dólares até US\$ 2,5 milhões, "entre capital próprio, fontes financeiras comunitárias e empréstimos da banca formal" (REA CAMPOS, 2016, p. 380).
} 
política, tem sido reconhecida pelo governo e é ilustrada pelos autores da pesquisa no seguinte episódio:

O ex-embaixador boliviano na China, Fernando Rodríguez, foi assessorado durante sua investidura no país asiático por Justina Aguilar, uma "senhora de pollera" - o nome hoje politicamente correto para referir-se às cholas - originária da comunidade de Tiquina, às margens do lago Titicaca, que exporta lã de alpaca à China. Por meio da senhora Aguilar, o embaixador Rodríguez travou contato com os círculos financeiros chineses e de seus representantes políticos. (TASSI et al., 2012, p. 99-100, tradução nossa).

As facilidades oferecidas pelo capital chinês com a abertura comercial no início desse século constituem outro fator que permitiu maior capitalização aos agentes que já haviam passado por uma acumulação prévia:

Tal situação se viu potencializada com as facilidades comerciais que começou a oferecer o país asiático, como contatos diretos com empresários chineses, facilidades de pagamentos de mercadorias e uma rede de tradutores chineses que atuam como intermediários culturais. Assim, desde os anos 2000 comerciantes aimarás principalmente, que contam com volumes de capital líquido que flutuam entre 50 mil dólares e 2,5 milhões de dólares, conseguiram estabelecer vínculos diretos com empresários asiáticos e criar convênios diretos, exclusivos e duradouros favorecidos pela flexibilidade dos empresários chineses de adequar-se às demandas e gostos de seus clientes: os comerciantes aimarás, que conquistaram um vasto conhecimento sobre os gostos de seus clientes nacionais e estrangeiros (...) ao ponto de registrar os produtos chineses que compram com sua própria marca, o que os tornam exclusivos. (REA CAMPOS, 2016, p. 393, tradução nossa).

A ascensão dessa nova camada da pequena burguesia comercial, com laços globalizados, também encontra paralelo com a ascensão de setores de transportadores, construção civil, cocaleiros e mineiros cooperativistas. Sua especificidade está na origem popular indígena: a maioria se identifica como aimarás ou quéchuas, possuem orgulho de suas raízes, visível na ostentação de indumentária e na participação ativa em festas e celebrações comunitárias, e possuem identidade de interesses com os objetivos políticos do $\mathrm{MAS}^{16}$, que buscava seu apoio eleitoral para se manter no poder. Alguns desses agentes econômicos, aliás, começam a penetrar os mercados do Brasil e Argentina através do comércio entre fronteiras, aproveitando a posição da Bolívia como país de trânsito do fluxo de capitais do Pacífico para o Atlântico e a consequente melhoria do sistema de transportes.

Assim, diferente dos comerciantes tradicionais que controlam o mercado local dentro dos limites nacionais, estes comerciantes aimarás transcenderam as fronteiras nacionais e conseguiram se converter em agentes econômicos globais e competitivos

\footnotetext{
${ }^{16}$ Embora isso não signifique alinhamento automático. Um exemplo disso foi a derrota de Evo Morales no referendo de janeiro de 2016, que lhe permitiria candidatar-se indefinidamente.
} 
que se movem entre o local, o nacional e o internacional. (REA CAMPOS, 2016, p. 396 , tradução nossa).

Ademais, segundo estudiosos, essa nova camada pequeno-burguesa diferencia-se das antigas elites econômicas bolivianas por se tratar de "um tipo de empresários mais austeros e populares que não se exibem em Miami e vivem com modéstia, como os cooperativistas mineiros, comerciantes urbanos e produtores rurais que o Estado articula para garantir-se uma base social de apoio com poder econômico e produtivo" (Machado \& Zibechi: 2016, p. 204, tradução nossa). Segue a mesma linha o ex-vice-presidente Garcia Linera, quando constata:

Há a emergência de um novo tipo de empresariado de origem, digamos assim, mais popular, recente, dos últimos trinta anos, que emerge com outra mentalidade, mais austera, mais clássica no sentido weberiano do termo, mais poupadora, não exiba seu dinheiro em gigantescas mansões nem vai a Miami a cada fim de semana, poupa e poupa, e segue comendo com a modéstia de quando surgiu da classe popular, vive no mesmo quartinho e na mesma vizinhança de vinte anos atrás, mas tem mais dinheiro que todos os outros juntos. (LINERA, 2009, p. 108, tradução nossa).

Embora a acumulação desses setores indígenas não seja um fenômeno recente e tenha sua dinâmica própria, independente dos atos governamentais, é certo dizer que o governo Morales representou o empoderamento político dessa nova pequena burguesia, que se vê prestigiada e incentivada a internacionalizar suas atividades, operando em fluxos internacionais de comércio e, portanto, interessada na abertura comercial e em regras estatais que fortaleçam a mercantilização.

Rea Campos define tal setor como uma protoburguesia, isto é, um estrato social que almeja alcançar um status social e cultural estabelecido, mas que até então está em vias de sêlo, não estando totalmente integrada à estrutura formal das classes médias.

Em sua condição de pequenos burgueses comerciais de origem aimará, têm o controle de uma parte do capital comercial e em alguns casos - ainda muito escassos - dos meios de produção e do controle de terceiros (proletários informais), mas ainda distantes do controle de um pessoal organizado burocraticamente, pois a relação trabalhista com seus empregados está mediada, principalmente, pelas relações de parentesco ritual (compadres-afilhados). Por último, dado que sua atividade comercial, devido à expansão e formalização que experimentam, requer cada vez maior domínio de conhecimentos contábeis e comerciais, investem na educação de seus filhos, não só para que estes obtenham a aceitabilidade do grupo de referência (a pequena burguesia não indígena), mas também com a esperança de tornar mais sustentáveis e rentáveis seus negócios a médio prazo. (REA CAMPOS, 2016, p. 402, tradução nossa). 
No entanto, essa burguesia emergente até aquele momento jogava um papel intermediário (mesmo que politicamente relevante) no bloco de forças sociais articulado pelo governo evista, como deixa claro o seguinte trecho:

\begin{abstract}
No contexto analisado, se pode afirmar que o capitalismo boliviano, o padrão de desenvolvimento, consiste em um padrão primário-exportador, agora controlado hegemonicamente pelo Estado, modelo de estatismo econômico, mas com uma adição: a intermediação comercial está nas mãos de uma variedade de burguesias cholas, burguesias emergentes, empresariados aimarás ou burguesias populares, todas de alma neoliberal. (PIEB, Temas de Debate, n $^{\circ} 21,2013$, tradução nossa).
\end{abstract}

Os germes dessa protoburguesia antecedem o governo do MAS, porém o controle do aparato estatal por um partido de caráter camponês pequeno-proprietário significou uma mudança qualitativa em seu processo de acumulação, pois as políticas públicas postas em prática visam principalmente facilitar tal processo: desde os relaxamentos da legislação ambiental e trabalhista, facilidades de crédito, ligação com os fluxos de comércio internacionais e até mesmo o prestígio oficial conferido à manifestações culturais de origem popular, mostram que essas novas camadas burguesas, ainda que estejam num processo de constituição em novas classes dominantes, integrava-se como a principal fonte de inspiração ideológica e o núcleo duro da base social do evismo.

\title{
4 CAPITAL CHINÊS NA BOLÍVIA
}

O estreitamento das relações entre China e Bolívia, em consonância com os objetivos estratégicos da primeira para a região e com o projeto político do bloco no poder da segunda, passa a se dar de forma mais visível a partir do ano de 2011 e alcança um ponto de inflexão a partir de 2015. Apenas em 2011, houve a visita do presidente Evo Morales à China, respondida, alguns meses depois, pela visita do Vice-Primeiro-Ministro chinês Hui Liangyu à Bolívia. Na primeira ocasião, Evo deixou claro o interesse do seu governo pelo capital chinês: “Temos recursos naturais à flor da terra como o lítio, o ferro, o petróleo e outros, cujo desenvolvimento precisa de investimentos" (CARPIO, 2016, p. 6, tradução nossa).

A presença chinesa na Bolívia segue alguns dos grandes padrões vistos no restante da América Latina, mas com algumas diferenças importantes. Por exemplo, os fluxos de IEDs para o país andino são insignificantes comparados com o montante total para a região: de acordo com Agramonte \& Bonifaz (2018, p. 86), eles não chegam a $1 \%$ do total (5\% do total que a Bolívia recebe, a grande maioria de países europeus), embora sejam altamente concentrados no setor de mineração e hidrocarbonetos (97\% do total). A conclusão dos 
autores é que: "A presença de empresas chinesas em forma de IED é quase inexistente" (p. 89, tradução nossa). A principal fonte de capital chinês na Bolívia provém de instituições financeiras estatais, como o Eximbank.

Quanto ao comércio, as importações bolivianas da China seguiram a tendência regional constantemente ao ponto de, a partir de 2015, esta ter se convertido na principal origem das importações bolivianas. Quanto as exportações, constituídas em $98 \%$ de bens primários minerais, a China integra apenas o quinto principal destino das exportações bolivianas, atrás de Brasil, Argentina, Estados Unidos e Colômbia.

É na presença de suas empresas que a influência chinesa se torna mais visível na Bolívia. Uma característica crucial na atuação dessas empresas é que seu principal cliente é o próprio Estado boliviano, que as contrata para realizar grandes obras de engenharia, energia e comunicações. Para financiar esses serviços, chama a atenção que, ao contrário da tendência regional, o total de empréstimos do governo chinês seja menos da metade (43\%), o resto pago pelo próprio governo boliviano ou por empréstimos de organismos multilaterais. Outro dado que chama a atenção é que apenas $16 \%$ de todos os contratos realizados com essas empresas foram feitos com licitação, o restante feito por convite direto, sob a modalidade conhecida como chave em mão.

As principais empresas chinesas operando hoje na Bolívia (Sinohydro, Sinopec, China International and Electric Corp - CWE, CAMC Engineering, China Railway etc.) estão presentes em todas as regiões do país e nos setores econômicos mais importantes, com atuação destacadas em alguns dos projetos mais controversos levados a cabo na Amazônia boliviana. Estão investindo em obras de construção de represas para a geração de energia (como as projetadas centrais de Cachuela Esperanza e Rio Grande-Rositas) ou estradas, como a de Rurrenabaque-Riberalta, próxima ao Parque Nacional Madidi. Sua atuação vem sendo alvo de um crescente questionamento de movimentos sociais e sindicais bolivianos, que denunciam as diversas violações de direitos trabalhistas e da legislação ambiental ${ }^{17}$.

Alguns dos projetos citados fazem parte de diversos planos de integração física do continente sul-americano tais como os corredores bioceânicos constantes no plano IIRSA (Iniciativa para a Integração Regional Sul-Americana), cujo objetivo é interligar as economias

\footnotetext{
${ }^{17}$ Por exemplo, o contrato entre a estatal boliviana YPFB e as chinesas Sinopec e BGP para a busca de recursos de hidrocarbonetos na região amazônica prevê que estas realizem tarefas de sondagem em dois blocos no norte amazônico, o que implicará no uso de dinamite para explosões subterrâneas. No entanto, representantes do povo indígena Tacana, na bacia do rio Madre de Dios, denunciam que essas empresas estão descumprindo os acordos de minimização de impacto ambiental e preservação da biodiversidade em seu território, comprometendo sua principal fonte de subsistência, as árvores de castanha. Para mais informações, ver https://cedib.org/post_type_titulares/inversiones-chinas-en-bolivia-informe-denuncia-danos-ambientales-enterritorio-indigena-mongabay-latam12-12-18/. Consultado em: 13/12/2019.
} 
da região aos centros dinâmicos da economia internacional, reduzindo o tempo de transporte das mercadorias e facilitando o acesso de multinacionais a regiões ricas em recursos naturais.

Refletindo os objetivos globais do seu governo, as empresas chinesas passaram a atuar firmemente para obter o maior número possível de contratos que envolvam esses projetos de integração, no que podemos supor que seja parte de uma política coordenada para garantir o acesso aos recursos da região e investimentos lucrativos, como fica evidente com a seguinte fala de Li Wei, principal executivo da multinacional chinesa Sinohydro:

\begin{abstract}
Em todas as grandes licitações que haja na Bolívia, iremos entrar para competir com nossa experiência. Contamos com 55 milhões em equipamento pesado. Temos mais de 700 máquinas. Isso nos dá uma vantagem competitiva porque há empresas transnacionais que não estão aqui. Temos uma logística armada para descarregar nosso equipamento e pessoal em qualquer rincão da Bolívia. (In: CARPIO, 2016, p. 10 , tradução nossa).
\end{abstract}

Para esse objetivo ambicioso, tais empresas contam tanto com o financiamento do governo chinês quanto com o beneplácito do governo local. Um exemplo que ilustra esse fato foi a lei emitida pelo o governo boliviano, para facilitar a atuação das empresas chinesas e o acesso aos empréstimos do governo chinês: Decreto Supremo 2574, de novembro de 2015, cujo objetivo era explicitado logo nas primeiras linhas:

\footnotetext{
Autorizar la contratación de obras, bienes y servicios, bajo procedimientos y condiciones específicas para la ejecución de proyectos a financiarse en el marco de Contratos de Préstamo a ser suscritos entre el Estado Plurinacional de Bolivia y el Banco de Exportaciones e Importaciones de la República Popular China EXIMBANK. (BOLÍVIA, 2015).
}

Além disso, no ano de 2015, o governo boliviano conseguiu obter da China um acordo que lhe concedia um crédito global de até 7 bilhões de dólares para o financiamento de projetos de infraestrutura e energia elétrica, a serem negociados um por um com a criação de comissões específicas nos ministérios correspondentes, com taxas de juros que variam de $1 \%$, $2,5 \%$ a $4 \%$, bem como a exigência desses projetos serem aprovados pelo Legislativo (CARPIO, 2016, p. 11).

O pouco investimento em IED das empresas chinesas e o papel protagonista que a diplomacia tem jogado na aproximação entre ambos os países evidenciam, no caso boliviano, os grandes esforços por parte da China, de ganhar a simpatia e apoio entre atores locais para a projeção de seus interesses econômicos, obtidos mediante a reafirmação de construção de relações horizontais sem imposições e de "soberania" do Estado, o que se harmonizava perfeitamente com as concepções estratégicas do partido governante MAS. 
O principal símbolo do estreitamento das relações foi o lançamento, em 2013, do satélite espacial Tupac Katari, construído pela Academia Chinesa de Tecnologia Espacial, por meio de empréstimo de 251 milhões de dólares, para prestar serviços de telecomunicações de celular, TV e internet. Além das compras de equipamento para as forças armadas e para a petrolífera estatal YPFB, as diversas modalidades de empréstimos e financiamentos para a construção de estradas e projetos para a exploração de recursos como o lítio, projetam tornar a China a maior credora da dívida externa boliviana, que pode alcançar 18 bilhões de dólares nos próximos anos.

\section{CONCLUSÃO}

A ascensão vertiginosa dos investimentos chineses em todo o mundo, aliada ao relativo declínio político-econômico dos EUA (embora esta ainda continue a ser a maior potência militar) nos permite afirmar que o mundo entra em uma fase de caos sistêmico, de acordo com o esquema teórico levantado por Arrighi (2012). O tempo de duração desse caos sistêmico e a nova configuração mundial do capitalismo que surgirá dele ainda são uma incógnita, mas, a partir da análise de suas tendências, o pesquisador social pode arriscar-se à alguns diagnósticos a partir de seus efeitos mais imediatos.

A América Latina historicamente inseriu-se na Divisão Internacional do Trabalho como fornecedora de matérias-primas baratas para os centros dinâmicos do sistema. No século $\mathrm{XX}$, diversos países empreenderam esforços de industrialização, nos quais alguns lograram construir expressivos parques indústrias e uma economia mais diversificada (casos do Brasil, México e Argentina). No entanto, múltiplas razões impediram esses países de competirem com êxito com as nações tecnologicamente mais avançadas, o que gerou sistemáticas crises em suas balanças de pagamento.

Com a demanda mundial por matérias-primas gerada pelo crescimento chinês, a América Latina tem visto sua inserção internacional voltar-se novamente para a produção de commodities, embora com importantes diferenças em relação ao padrão primário-exportador do passado. Essa nova inserção reedita, sob novos aspectos, importantes traços da Dependência como uma condição estrutural de nossas economias.

Por consequência, em virtude da importância que essas atividades econômicas desempenham para a estabilidade macroeconômica dos países latino-americanos, as frações das classes dominantes que controlam tais atividades adquirem poder cada vez maior dentro dos blocos dirigentes locais. Ironicamente, foram governos ditos de "esquerda" que na última década promoveram o avanço das atividades extrativistas, como o meio mais rápido e fácil de 
obter divisas para seus programas sociais e políticas de aumento de renda dos setores populares. Ao fazerem isso, revitalizaram frações das classes dominantes ligadas às formas mais extremas de exploração do trabalho, ideologicamente avessas à participação popular e afinadas ao setor financeiro do grande capital. Quando o cenário internacional deixou de ser favorável, essas frações burguesas lançam-se a uma ofensiva para retomar o pleno controle do aparato estatal e, com isso, promover uma série de ataques ao setor assalariado.

É o que testemunhamos na Bolívia recentemente, com o golpe cívico-militar empreendido a partir de setores da elite agroindustrial, apenas o exemplo mais recente do acirramento da luta de classes no continente. Embora política e ideologicamente afinadas com os EUA, essas frações burguesas extrativistas não parecem capazes de imprimir uma orientação diferente às tendências analisadas, já que os empréstimos chineses e as importações advindas desse país constituem uma importante fonte de financiamento para o Estado e setores mercantilizados das classes populares ${ }^{18}$. Portanto, embora no momento em que escrevemos ainda não esteja claro qual será a orientação do governo boliviano pós-golpe, a presença das empresas chinesas na Bolívia parece ser uma realidade que não mudará.

\section{REFERÊNCIAS}

ACOSTA, Alberto. O bem viver. São Paulo: Elefante, 2016.

AGRAMONT, Daniel.; BONIFAZ, Gustavo. El desembarco chino en América Latina y su manifestación en Bolívia. La Paz: Plural Editores, 2018.

ARRIGHI, Giovanni. Adam Smith em Pequim: origens e fundamentos do século XXI. São Paulo: Boitempo, 2008.

ARRIGHI, Giovanni. O longo século XX. Rio de Janeiro: Contraponto, 2012.

BOLÍVIA, Estado Plurinacional de. Decreto Supremo No 2574, 3 de noviembre de 2015.

CARPIO, Silvia Molina. La presencia china en Bolivia: Porqué el interés en una de las economías más pequeñas de la región? La Paz: Plataforma Energetica nº 15, junio de 2016.

CHINA'S Policy Paper on Latin America and the Caribbean, 05/11/2008. Disponível em: https://china.usc.edu/chinas-policy-paper-latin-america-and-caribbean.

\footnotetext{
${ }^{18}$ Além do fato de que, embora menos significativas se comparadas com países como o Brasil, as exportações agropecuárias bolivianas têm experimentado um aumento sistemático nos últimos anos. Ver, por exemplo, https://cedla.org/problematica-rural-y-agraria-prya/34636/larazon•bolivia-empezara-a-exportar-el-28-de-agostocarne-de-res-a-china. Visto em: 28/12/2019. Desse modo, parece ser um caminho lógico para as elites agroindústrias de Santa Cruz tentarem conquistar espaço dentro do enorme mercado chinês.
} 
CREUTZFELDT, Benjamin. China and the U.S in Latin America. Revista Científica General José Maria Córdova, Bogotá. v. 14, nº 17, 2016.

GIL, Aldo Durán. Bolívia: duas revoluções nacionalistas? Perspectivas, São Paulo, V. 33, p. 157-189, jan/jun 2008.

JABBOUR, Elias. China Hoje: Projeto nacional, desenvolvimento e socialismo de mercado. Campina Grande: Ed. UEPB, 2012.

KATZ, Claudio. Neoliberalismo, neodesenvolvimentismo, socialismo. São Paulo: Expressão Popular, 2016.

KISSINGER, Henry. Sobre a China. São Paulo: Objetiva, 2011.

LINERA, Alvaro. Garcia. El papel del Estado en el Modelo Nacional Productivo, Vicepresidencia del Estado Plurinacional, Discurso \& ponencias. N ${ }^{\circ}$ 6, La Paz, enero 20 de 2009.

LINERA, Alvaro. Geopolítica de la Amazônia. La Paz: Vicepresidencia de Estado, 2012.

LEÃO, Rodrigo P. F.; COSTA PINTO, Eduardo.; ACIOLY, Luciana (orgs.). A China na nova configuração global: Impactos políticos e econômicos. Brasília: IPEA, 2011.

LO BRUTO, Giuseppe.; MINUTTI, Eduardo. C. La cooperación de China en América Latina: hacia una Nueva Economia Estructural? Rev. Carta Internacional, Belo Horizonte, v. 13, n. 2, p. 123-146, 2018.

MACHADO, Decio.; ZIBECHI, Raúl. Cambiar el mundo desde arriba: Los limites del progresismo. La Paz: Cedla, 2016.

MORENO, Camila. O Brasil made in China: para pensar as configurações do capitalismo contemporâneo. São Paulo: Fundação Rosa Luxemburgo, 2015.

ORMACHEA S, Enrique.; RAMIREZ F, Nilton. Políticas agrárias del gobierno del MAS o la agenda del "poder empresarial-hacendal". Laz Paz: CEDLA, 2013.

PECEQUILO, C. S.; CARMO, C. A. A China, o sistema internacional e o Sul: ascensão pacífica? Brazilian Journal of International Relations. Marília, v. 3, nº 1, p. 31-69, jan-abr. 2014.

REA CAMPOS, Carmen Rosa. Complementando racionalidades: la nueva pequena burguesia aymará en Bolívia. Revista Mexicana de Sociologia. Mexico: 78, p. 375-407, jul-set 2016.

ROCHA, Felipe. Freitas.; BIELSCHOWSK, Ricardo. La búsqueda de China de recursos naturales en América Latina. Revista de la Cepal, nº 126, dez. 2018.

ROLDÁN, Adriana. et al. La presencia china en América Latina: comercio, inversión y cooperación económica. Bogotá: Konrad Adenauer Stiftung, 2016. 
SILVA, G. D.; GOMES, M. F. M.; TEIXEIRA, E. C. Efecto derrame del crecimiento de China en América del Sur: un análisis basado en el comercio internacional. Revista de la Cepal, $n^{\circ}$ 126, dez. 2018.

SVAMPA, Maristella. Del cambio de época al fin de ciclo. Buenos Aires: Edhasa, 2017.

TASSI, Nico (org). "Hacer plata sin plata": El desborde de los comerciantes populares en Bolívia. La Paz: Fundación Pieb, 2013.

El desborde económico popular en Bolívia: comerciantes aymaras en el mundo global. Revista Nueva Sociedad No 241, sep.-oct. 2012. Disponível em: http://www20.iadb.org/intal/catalogo/PE/2012/10495.pdf.

URQUIDI, Vivian. Movimento cocaleiro na Bolívia. São Paulo: Ed. Hucitec, 2007. 